\title{
Noise characteristics of an electromagnetic sea-ice thickness sounder on a fixed wing aircraft
}

\author{
Lasse Rabenstein $^{\mathrm{a}, \mathrm{d}, *}$, Stefan Hendricks ${ }^{\mathrm{a}}$, John Lobach ${ }^{\mathrm{b}}$, Christian Haas ${ }^{\mathrm{c}}$ \\ a Alfred Wegener Institute for Polar and Marine Research, Bremerhaven, Germany \\ b Ferra Dynamics Inc., Mississauga, Ontario, Canada \\ ' Department of Earth Sciences, University of Alberta, Edmonton, Alberta, Canada \\ d Institute of Geophysics, Swiss Federal Institute of Technology, Zurich, Switzerland
}

\section{A R T I C L E I N F O}

\section{Article history:}

Received 2 March 2010

Accepted 10 June 2011

Available online 1 July 2011

\section{Keywords:}

Sea-ice thickness

Airborne electromagnetics

3D modeling

Noise sources

\begin{abstract}
A B S T R A C T
In this paper, the noise sources of an airborne electromagnetic frequency domain instrument used to measure sea-ice thickness are studied. The antennas are mounted on the wings of an aircraft. The paper presents real data examples showing that strong noise limited the accuracy of the thickness measurement to $\pm 0.5 \mathrm{~m}$ in the best case. Even drift cor-rection and frequency filtering did not reduce the noise to a level necessary for sea ice thickness measurements with an accuracy of $0.1 \mathrm{~m}$. We show results of 3D finite element modeling of the coupling between transmitter and receiver coils and the aircraft, which indicate that wing flexure is the primary cause of the strong noise. Wing deflection angles below $5^{\circ}$ relative to the fuselage are large enough to cause changes higher than the wanted signal from the seawater under the ice. Wing flexure noise can be divided into an inductive and geometric contribution, both of the same order. Most of the wing flexure signal appears on the inphase component only, hence the quadrature component should be taken for sea ice thickness retrievals when wing flexure is present even when the inphase produces a larger ocean sig-nal. Results also show that pitch and roll movements of the aircraft and electromagnetic coupling between seawater and aircraft can contribute significantly to the total noise. For flight heights of $30 \mathrm{~m}$ over the ocean these effects can change the sig-nal by about $10 \%$ or more. For highly quantitative measurements like sea-ice thickness all these effects must be taken into account. We conclude that a fixed wing electromagnetic instrument for the purpose of measure-ments in a centimeter scale must include instrumentation to measure the relative position of the antenna coils with an accuracy of $1 / 10 \mathrm{~mm}$. Furthermore the antenna separation distance should be as large as possible in order to increase the measured ratio of secondary to primary magnetic field strength.
\end{abstract}

(c) 2011 Elsevier B.V. All rights reserved.

\section{Introduction}

With a rapidly changing climate in the Polar regions the need for a long range aircraft equipped with sea-ice thickness sensors emerged. Airborne electromagnetic induction (AEM) is one possible method and was already succesfully applied. To our knowledge all AEM surveys were done with instruments operating in the frequency domain (FD). During past sea-ice thickness studies mostly helicopter based instruments were used, either with a towed Bird (Haas et al., 2009; Kovacs et al., 1987) or fixed on the nose of a helicopter (Prinsenberg et al., 2002). With helicopter electromagnetics (HEM) a sea-ice thickness accuracy of $0.1 \mathrm{~m}$ can be reached (Haas et al., 2009; Pfaffling et al., 2007). In order to obtain relevant, statistically reliable mean sea-ice thickness information and to reach the thick and perennial sea-ice zones north of Greenland and Canada long AEM transects of about $800 \mathrm{~km}$ and more have to be flown,

\footnotetext{
* Corresponding author at: Alfred Wegener Institute for Polar and Marine Research, Bremerhaven, Germany. Tel.: +49 1777393942.

E-mail address: lasse.rabenstein@awi.de (L. Rabenstein).
}

too long for commonly available helicopters. Pioneering EM measurements of sea-ice thickness using a fixed-wing aircraft were done for the period of three winters $(1991,1993,1994)$ in the Baltic Sea, with the antennas mounted on the wing tips of a Twin Otter (Multala et al., Dec, 1996). Under best conditions (Multala et al., Dec, 1996) reached a thickness accuracy of $\pm 0.2 \mathrm{~m}$. The German Alfred Wegener Institute for Polar and Marine Research (AWI) regularly conducts geophysical and meteorological measurements using the "Polar 2", a Dornier 228 aircraft specially designed for operations in cold regions (e.g. Steinhage et al., 2001). Based on the experience from five years of successful helicopter EM sea-ice thickness measurements (e.g., Haas et al., 2006; Haas et al., 2008; Rabenstein et al., 2010) the development of an EM sea-ice system for the "Polar 2" was initiated. The idea was to have an instrument available for long term sea ice thickness studies on a seasonally repeating basis. The "Polar 2" has a significantly larger range than helicopters which offers the possibility to reach even remote areas of the Arctic Ocean where e.g. thicker and older multi year ice can be found. This would be the first fixed wing EM system dedicated to measurements of seasonal and inter annual sea ice thickness changes. 
The purpose of this paper is to study the characteristics of the "Polar 2" fixed wing EM prototype system, to name and quantify its major noise sources and to derive why its sea-ice thickness accuracy is lower than that of other existing AEM systems. Previous publications which introduced new EM systems mostly showed the positive aspects of the newly developed instruments, but a detailed analysis of obstacles which occurred during the development process or a quantification of the noise sources was rarely given. Therefore we present the major findings obtained during the development of the "Polar 2" prototype system so far, believing that this knowledge is useful for other future developments aiming in the same direction. The "Polar 2" system was studied during several test flights. Instead of presenting all of these test flights we choose two of them suitable to show the following effects: (1) signal change due to the metallic aircraft, (2) coupling effects between ocean and aircraft, as well as signal distortion due to (3) wing flexure and (4) pitch and roll movements of the aircraft. The first of the presented flights aimed on the accuracy of the system to measure ice thickness including all the above mentioned effects and the second to evaluate the effect of wing flexure. The first flight was performed in different altitudes over open ocean, where sea-ice thickness is zero and sea water conductivity known. Over open ocean the difference between flight height measured with the laser altimeter and flight height derived from the strength of the EM signal should be as small as possible and reflects the accuracy of the system to measure sea-ice thickness. The second test flight was performed in high altitudes of $600 \mathrm{~m}$, where the ocean response signal is negligible. It included alternating descending and ascending maneuvers in order to trigger inertia forces moving the wings up and down relative to the fuselage. In order to further quantify the signal distortions observed during the test flights the commercial Comsol-Multiphysics ${ }^{\circledR}$ 3D Finite Element (FEM) code was used to simulate the disturbing effects of the "Polar 2" with its complicated 3D geometry. The 3D FEM computer simulations are a core part of this study and we used them to extent the "Polar 2" case, where the installation of the antennas was constrained to existing hard points below the center of each wing, to the hypothetic case when the antennas were mounted at the wing tips, similar to the fixed wing EM system presented by (Poikonen et al., 1998) and (Levaniemi et al., 2009).

The procedure of sea ice thickness retrieval from AEM measurements is described by (Pfaffling et al., 2007) and (Haas et al., 2009). Basically sea ice thickness is derived by the difference of two distance measurements, a laser altimeter measures the distance to the uppermost snow or ice surface and the actual EM system estimates the distance to the underlying ocean, which can be taken as a homogeneously conductive halfspace. For a conductive halfspace the EM response, which depends on the halfspace conductivity and the height over the halfspace, can be calculated by an analytical 1D model (e,g, Ward and Hohmann, 1988). Hence, with known halfspace conductivity, the distance between instrument and halfspace can be directly derived from the EM signal strength. Whether the 1D model curve can be taken as a reference without any constraints in the case of a fixed wing antenna situation with the antennas close to the conductive aircraft will be clarified here. For a signal frequency of $1990 \mathrm{~Hz}$ used here, uncertainties in sea ice conductivtiy, which is on average 200 times smaller than that of sea-water, are negligible and lead to ice thickness errors of less than $0.1 \mathrm{~m}$ (Pfaffling et al., 2007). Therefore and for reasons of simplicity we restrain our accuracy and noise study to the case of flights over open water where we compare the results directly to an ice thickness of zero meters. Classical inversion methods which are usually applied for AEM data turned out to be less accurate than the one described here, even when they account for a conductive sea-ice layer (Pfaffling et al., 2007). Furthermore the AEM method only resolves sea ice thickness features larger than the footprint of the system, which is for a VCP configuration $\sim 1.35$ times the height over the ocean (Kovacs et al., 1995).
Generally, frequency domain EM measurements are relative measurements of the ratio of the secondary magnetic field to the actively transmitted primary magnetic field. The secondary field emerges from induction in conductive bodies within range of the transmitter. In this study we consider every signal emerging from induced magnetic fields in the aircraft or in the ocean as secondary field signals and quote them in parts per million ( $\mathrm{ppm}$ ) of the primary field. In EM-Bird frequency domain instruments the primary signal usually is attenuated physically by a compensation coil close to the receiver so that a pure secondary field is recorded. Here we follow different approaches by either compensating the primary signal digitally during flight or by subtracting an analytically determined primary field voltage in a post flight processing step. With the post processing approach all signals emerging from the metallic aircraft body are included in the secondary signal whereas the digital compensation method tries to compensate the disturbing signals from the aircraft during a high altitude adjustment procedure.

Since EM measurements are sensitive to conductive bodies, the metallic aircraft in the immediate proximity to the antennas strongly influences the signal. Former studies by (Poikonen et al., 1998) or (Suppala et al., 2005) dealt with the contribution of the conductive aircraft to the signal of a fixed wing EM system and found that the aircraft anomaly is fairly constant and that most of it can be reduced by a proper calibration. Non constant aircraft anomalies may be caused by inductive coupling between ground and aircraft. (Suppala et al., 2005) found that for the fixed wing EM system of the Finish Geological Survey (GTK) a coupling between aircraft and ground can be neglected for the purpose of geological mapping. However, sea-ice thickness measurements are conducted over sea water which is in relation to most geological materials highly conductive $(2.0-4.5 \mathrm{~S} / \mathrm{m})$ and we expect a significant amount of coupling between ocean and aircraft. If this is true, simple 1D models cannot be taken as a reference for the EM response over the ocean. Instead, measurement results have to be compared with 3D models where the conductive aircraft body is included. Motivated by previous studies by (Fitterman and Yin, 2004) another aim is on the effect of pitch, roll and yaw in the presence of the conductive aircraft on the EM signal.

The "Data and method" chapter of this paper introduces the prototype airborne EM instrument, which was used during the test flight, with all important technical parameters and recorded data streams. Furthermore all processing steps, converting raw voltages into sea-ice thickness, are explained. The section concludes with a description of the geometry and the settings of the 3D model study. In total three model studies were performed in order to quantify the effect of induced currents in the aircraft body, the effect of pitch \& roll and the effect of wing flexure. Each of these studies was performed for the geometry of the "Polar 2" prototype, with the antennas mounted below the center of each wing and for a hypothetical realization with the antennas mounted at the wing tip.

The "Results" part of this paper is divided into a measurement and modeling part. In the measurement part we show the results of two test flights and compare the results of the first flight with a theoretical 1D model. Furthermore the potential sea-ice thickness accuracy of the prototype system is presented. Finally the results of the three FEM model studies are presented.

In the "Discussion" part we compare the importance of the particular processing steps and evaluate their relative relevance for the total signal. Furthermore the applicability of the FEM results to the test flight data is discussed. The paper concludes with a short summary and suggestions for future fixed wing sea-ice thickness EM instruments.

\section{Data and methods}

\subsection{Prototype instrument}

For every aircraft the construction and mounting of an AEM system has to be solved and licensed individually. The design of the fixed wing 
Table 1

Technical parameters of the prototype fixed wing EM system.

\begin{tabular}{ll}
\hline Altimeter & $100 \mathrm{~Hz}$ laser altimeter \\
Domain & Frequency \\
Frequency range & One frequency of $1990 \mathrm{~Hz}$ \\
Coil spacing & $11.6 \mathrm{~m}$ \\
Coil configuration & Vertical coplanar \\
Magnetic moment & $495 \mathrm{Am}^{2}$ \\
Sampling rate & $10 \mathrm{~Hz}$ \\
Range of Dornier 228 & 540 to 1400 nautical miles \\
Operation flight height & Nominally $100 \mathrm{ft}$ \\
Operation speed & 80 to 100 knots \\
\hline
\end{tabular}

system on the Dornier 228 polar aircraft of the AWI was constrained by available hard points and the requirement of easy and inexpensive installation. Two pylons, one under each wing, already existed on the aircraft for installation of several other geophysical instruments, e.g. a ground penetrating radar (Steinhage et al., 2001). The most feasible and cost saving realization with respect to air certification and aerodynamics was a pair of two vertical coplanar (VCP) coils mounted below each of the pylons, starboard the receiver ( $\mathrm{Rx}$ ) coil and port the transmitter (Tx) coil. Tx and Rx have a coil separation distance of $11.6 \mathrm{~m}$. The coil separation distance $d$ is a critical design aspect since the relative EM signal, which is secondary divided by primary magnetic field, increases with $d^{3}$. Unfortunately the existing hard points did not allow for a larger separation of the antennas, and the ideal case of a wing tip mounting was not realizable. The Tx-coil of a VCP configuration creates a horizontal magnetic dipole with the advantage of a weaker coupling with the horizontally oriented wings than a vertical magnetic dipole (Levaniemi et al., 2009). Further technical parameters are listed in Table 1. The signal frequency of $1990 \mathrm{~Hz}$ creates an inphase response signal over a homogeneous halfspace with conductivities typical for seawater $(2.0-4.5 \mathrm{~S} / \mathrm{m})$ which is close to the asymptotic maximum of the inphase signal theoretically reached for higher frequencies. At the same time the frequency of $1990 \mathrm{~Hz}$ is insensitive to the sea-ice layer with typical conductivities of $10-50 \mathrm{mS} / \mathrm{m}$. The antenna coils itself are enclosed by a specially designed "teardrop-shaped" minimum drag shell and have a diameter of $0.4 \mathrm{~m}$ which is a compromise between a large enough dipole moment and not too much drag. The system itself is shown in Fig. 1 together with a schematic diagram of all important electronic components. The fixed wing system uses an electrical compensation method to attenuate the primary field at the receiver coil. Such an approach was already used by e.g. (Levaniemi et al., 2009) for the construction of the airborne EM system "AEM-05", operated by the British Geological Survey (BGS) and the Finish Geological Survey (GTK). In total four EM signals of $1990 \mathrm{~Hz}$ are recorded: The transmitter reference voltage ( $U_{r e f}$ ) by a single loop of wire around the Tx-coil, the voltage used for compensation $\left(U_{\text {comp }}\right)$, the receiver voltage $\left(U_{p s}\right)$ generated by the primary and secondary fields, and the amplified residual voltage after compensation $\left(U_{s}\right)$ caused by the secondary field. The $1990 \mathrm{~Hz}$ voltage of each signal is estimated over a period of $100 \mathrm{~ms}$ by the acquisition system. There are 199 periods in each $100 \mathrm{~ms}$ measurement period which can be considered a form of stacking to a final sampling rate of $10 \mathrm{~Hz}$. Furthermore a laser altimeter records the altitude of the aircraft with an accuracy of $0.02 \mathrm{~m}$. To correct for orientation effects, pitch, roll and yaw of the aircraft are recorded. In addition basic meteorological data are routinely recorded during flight.

\subsection{Data processing}

\subsubsection{Phasing}

The recorded secondary voltage $U_{s}$ is divided into two parts, one $180^{\circ}$ out of phase with the transmitter signal (called Inphase) and another $90^{\circ}$ out of phase with the transmitter signal (called Quadrature). This expression is alternatively to the Phase $(\Theta)$ and Amplitude $(A)$ description of time harmonic signals. Calculation of Inphase $(I)$ and Quadrature $(Q)$ follows

$$
\begin{aligned}
& I=A \cdot \sin (\Theta) \\
& Q=A \cdot \cos (\Theta)
\end{aligned}
$$

The relative amplitudes of $I$ and $Q$ depend on the conductivity and distance of the medium causing the EM response. In free space, where no conductors are present, no secondary magnetic field is induced and only voltages due to the primary field are recorded at the receiver coil. Theoretically the primary field is $100 \%$ on the I component of the receiver voltage (Telford et al., 1990, p.351). But in reality antenna coils are not perfect conductors, henceforth $Q$ and $I$ components are recorded. Furthermore, with the presence of the metallic aircraft a true free space situation cannot be assumed anyway. However, in order to apply Eqs. (1) and (2) the phase angle $\Theta$ has to be known. Every electronic component involved in the signal recording (e.g. amplifiers, A/D converters) and the presence of the aircraft body cause additional phase shifts. To correct for these unknown shifts a 10 second lasting $Q$-voltage pulse is added to the transmitter signal at the beginning and end of each test flight maneuver. During data processing, $\Theta$ is adjusted such that the $Q$-pulse appears on the Quadrature trace only. With these processing steps the system phase can be determined. The effect of phase correction on raw voltage data is illustrated in Figure 2a and $2 \mathrm{~b}$.

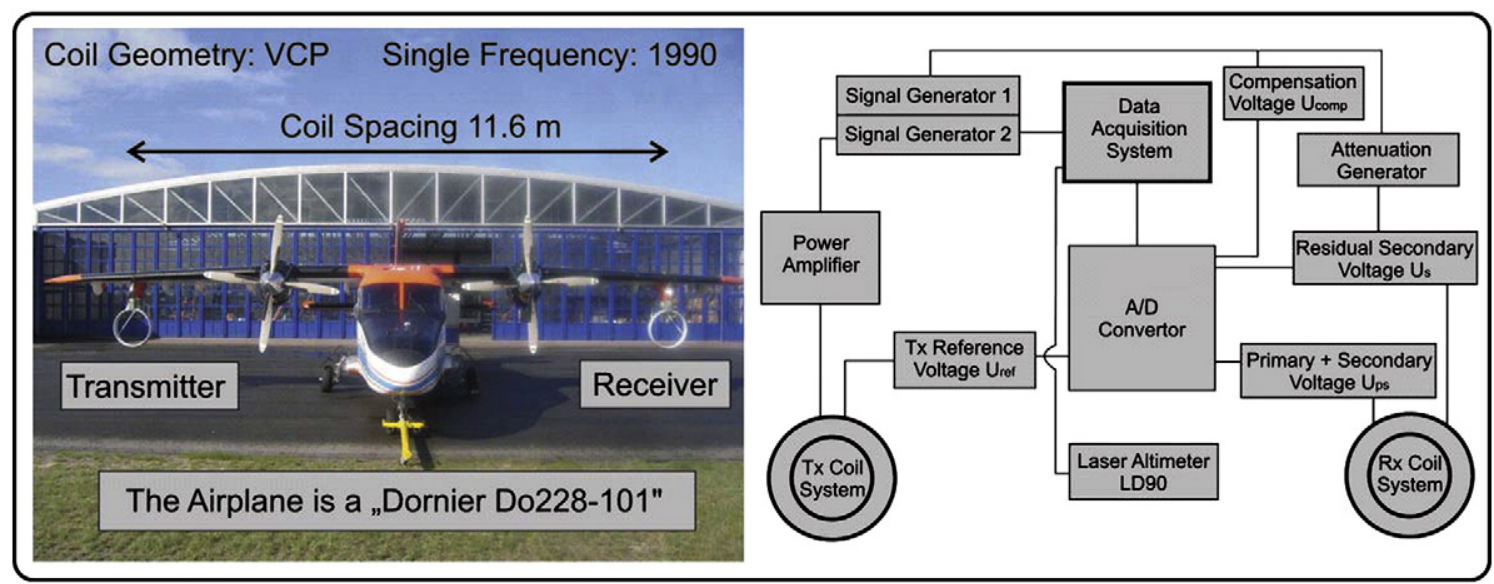

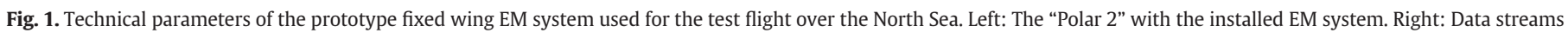
and important electronic components. Four data streams are recorded: 1. Tx reference voltage, 2. Rx Primary voltage, 3. Rx Attenuated Primary voltage, 4. Attenuation Signal. 


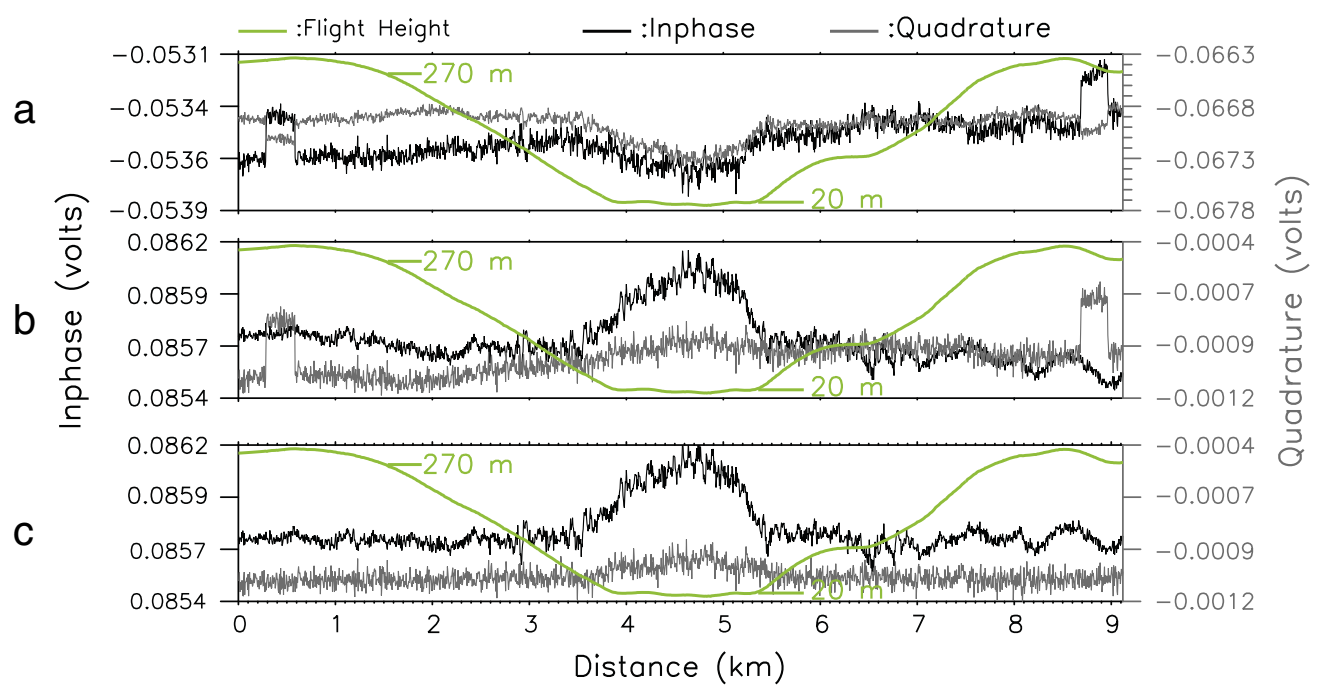

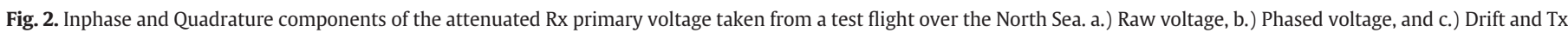
corrected voltage.

\subsection{2. $T x$ correction}

A variety of noise sources cause unwanted undulations on the $\mathrm{Rx}$ signal. Some of these undulations are visible on both, Rx signal and Tx reference signal. They are based on unstable transmitter voltages. One example is shown in Fig. 3 where some changes of the Tx voltage are directly visible on the raw $\mathrm{Rx}$ voltage. These $\mathrm{Rx}$ voltage changes can theoretically be derived from the Tx reference signal which would allow for an exact correction of such Tx undulations. But in reality the parameters of the antennas are constantly changing due to e.g. heating of the coils and we have to use a less direct approach by fitting the following equation to a constant base voltage as follows:

$U_{p s}-F * U_{\text {ref }}=U_{p s \_b a s e}$

$U_{p s_{-} \text {base }}$ is the voltage of the receiver at the beginning of the flight section and $F$ a linear conversion factor which should ideally be constant and known, if the systems physical parameters would not change. Here the best $F$ value is determined by a fitting algorithm. In Fig. 3 it is also visible that the sensitivity of the single reference loop to the sea water (homogeneous conducting halfspace) is negligible even for low flight altitudes and we consider the reference signal as free of any secondary EM response. The Tx correction improves the receiver signal slightly.

\subsubsection{Drift correction}

After Tx correction there is still a significant amount of drift visible on the receiver output. This electronic drift mainly results from changes of the operating temperature of Tx- and Rx-coil. After a warm-up period this drift becomes weaker and more linear. At the beginning and end of each survey flight several minutes of free space signal are recorded in high altitudes of more than $300 \mathrm{~m}$. The free space signal defines a line for which the relative signal $U_{s} / U_{p}$ can be set to zero. This zero line can be estimated for the entire flight by fitting a polynomial function of the third order to the free space sections at the beginning and end of the transect. This results in an interpolation of the zero line for the low altitude survey flight section. With a known zero line the signal drift can be reduced for the entire flight. The effect of drift- and Tx-correction is illustrated in Figure 2c.

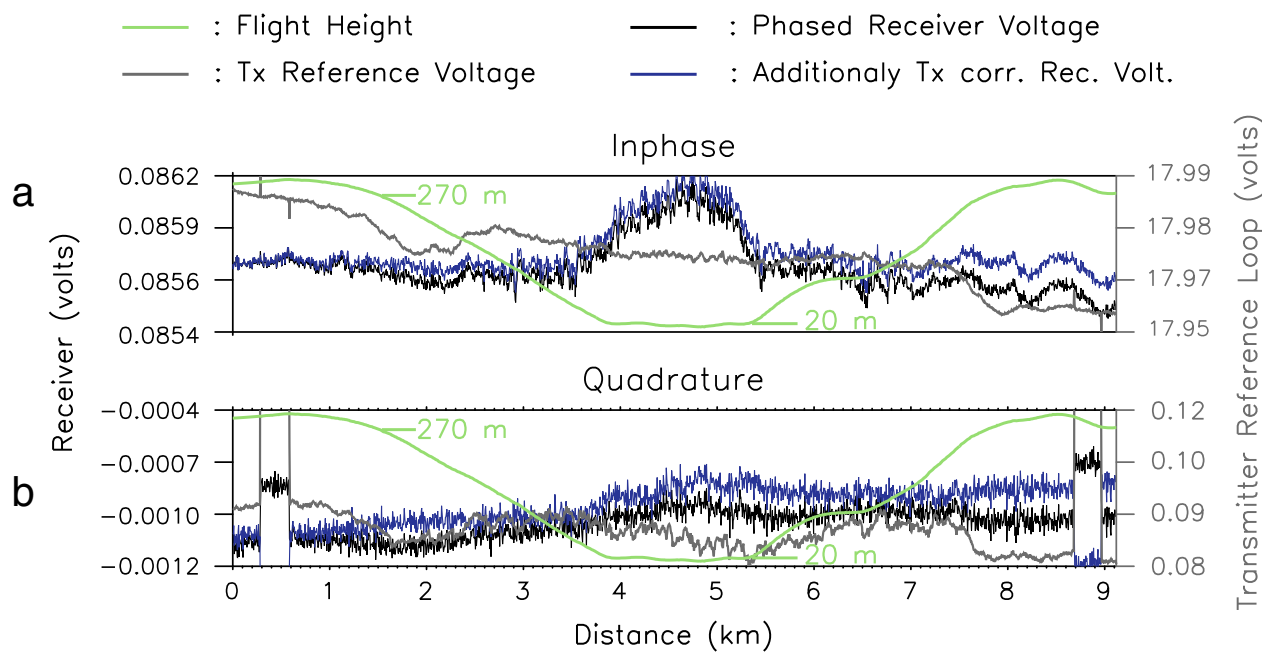

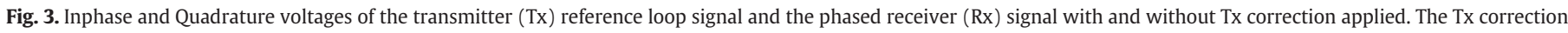

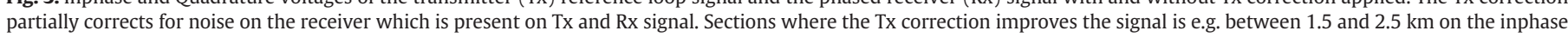
signal and at $7.5 \mathrm{~km}$ on the quadrature signal. 


\subsubsection{Conversion to ppm}

After phasing and drift correction the raw receiver voltages are converted to relative secondary field strengths $(S)$ in parts per million $(\mathrm{ppm})$. The conversion is based on the simple formula:

$\frac{U_{\text {rec }}}{10^{6}(\mathrm{ppm})}=\frac{U_{\mathrm{sec}}}{S(\mathrm{ppm})}$

where $S(\mathrm{ppm})$ is the secondary field signal at the receiver in parts per million of the primary field, $U_{r e c}$ is the primary plus secondary receiver voltage in free space recorded in altitudes higher than $300 \mathrm{~m}$ and $U_{\text {sec }}$ is the secondary voltage either taken from the digitally compensated voltage $U_{s}$ or determined by a calculated primary voltage $U_{\text {calc. }}$. In the following we take $U_{\text {sec }}$ as derived with the calculated voltage $U_{\text {calc }}$ since then $U_{\text {sec }}$ includes the secondary field from the aircraft.

$U_{\text {sec }}=U_{P S}-U_{\text {calc }}$

with $U_{\text {calc }}$ the primary voltage which is theoretically induced in the receiver coil in free space under absence of an aircraft. $U_{\text {calc }}$ is determined using the mutual impedance approach for two loops in free space (Wait, 1955). In other frequency domain EM systems, e.g. helicopter birds, a determination of $U_{\text {calc }}$ is not necessary since a bucking coil attenuates the primary field at the location of the receiver physically so that $U_{s e c}$ is measured directly. However, the mutual impedance approach is based on the equation:

$U_{\text {calc }}=Z_{0} * I_{T x}$

where $Z_{0}$ is the mutual impedance between transmitter and receiver coil and $I_{T x}$ is the current strength in the transmitter coil. $Z_{0}$ in free space is determined by (Keller and Frischknecht, 1966):

$Z_{0}=\frac{i \omega \mu_{0}}{4 \pi d^{3}}\left(N_{T x} \pi r_{T x}^{2}\right)\left(N_{R x} \pi r_{R x}^{2}\right)$

with $\omega$ the circular frequency, $\mu_{0}$ the magnetic permeability of vacuum, $N_{T x}$ and $N_{R x}$ the number of turns of transmitter and receiver coil respectively, $r_{T x}$ and $r_{R x}$ the radius of transmitter and receiver coil and $d$ the distance between transmitter and receiver. The transmitter current is determined by

$I_{T x}=U_{r e f} * N_{T x} / i \omega L_{T x}$

where $U_{\text {ref }}$ is the voltage on the reference loop of the transmitter and $L_{T x}$ the inductance of the transmitter coil.

For the coil system of the "Polar 2" prototype system $U_{\text {calc }}$ is smaller than $U_{\text {rec }}$ showing that the conductive aircraft body has an amplifying effect on the Rx signal. Consequently $S(\mathrm{ppm})$ in free space is not zero but includes the response of the aircraft to the primary field. As a first approach we consider this aircraft response $\left(S_{A}\right)$ as a constant off set to the signal and simply subtract it from the complete trace in order to eliminate $S_{A}$ but keep the ocean response $S_{O}$ for the lower altitudes.

\subsubsection{Pitch and roll correction}

An Inertial Navigation System (INS) records pitch, roll and yaw of the aircraft with a sampling rate of $50 \mathrm{~Hz}$. Based on these data the tilted laser height $h_{m}$ can be corrected for deviations from the nadir direction by a rotation operation (e.g., Fitterman and Yin, 2004):

$$
\left(\begin{array}{c}
x \\
y \\
h_{c}
\end{array}\right)=R_{\text {pitch }} R_{\text {roll }}\left(\begin{array}{c}
0 \\
0 \\
h_{m}
\end{array}\right)
$$

where $h_{c}$ is the corrected laser height and $R$ is the rotation matrix for roll and pitch respectively. Yaw has no influence on the laser height as the problem is symmetrical around the $\mathrm{z}$-axis (=height).
The EM signal itself changes with pitch and roll too. For the half space situation over the ocean yaw again has no influence on the EM signal. To correct for the effect of roll and pitch we developed a system specific chart on the basis of the 3D FEM model results. From this chart EM correction factors can be taken for every combination of roll, pitch and height. The correction factor does not only consider the geometrical displacement of the antenna coils but it additionally takes into account the change of inductive processes in ocean and aircraft under tilted conditions. The creation of the chart is explained in Chapter 3.2.2.

\subsubsection{Ice thickness retrieval}

As mentioned in the Introduction a 1D model solution of the EM response for different instrument heights over a homogeneous halfspace can be taken to derive the distance to the sea water from the ocean response signal $S_{O}$. Together with every sample of $S_{O}$ a laser height $h_{c}$ is recorded. When $I$ and $Q$ of $S_{O}$ are plotted versus $h_{c}$ and as long as there is open water under the instrument all data points lie on the respective model curves following an exponential decrease with increasing laser height. When sea ice is present a $S_{O}$ versus $h_{c}$ data point do not lie on the model curve any longer. Instead, for a given laser height a smaller $S_{O}$ is measured. The 1D model curve indicate the true height over the ocean halfspace $h_{e m}$ for a given $S_{O}$. This height is subtracted from the corresponding laser height which results in ice thickness. However, as described in the Results section the 1D model curve is better replaced by a model curve from more complex 3D FEM model.

\subsection{Finite element model study}

\subsubsection{Model description}

For the FEM models the commercial software package ComsolMultiphysics ${ }^{\circledR}$ was used. All model parameters are shown in Fig. 4. The geometry of the FEM model consists of two homogeneous half spaces, the upper one with a conductivity of $0 \mathrm{~S} / \mathrm{m}$ and the lower one with a sea-water conductivity of $4.2 \mathrm{~S} / \mathrm{m}$. Two vertical coils, representing transmitter and receiver, were placed (1) under the two wings and (2) at the wingtips of a solid aircraft model, which was designed to resemble the geometry of the "Polar2" as good as possible (see Fig. 5). The aircraft conductivity was set to the conductivity of Aluminum which is $3.77 \cdot 10^{7} \mathrm{~S} / \mathrm{m}$. For the given frequency of $1990 \mathrm{~Hz}$ this results in a skin depth of below one centimeter. Therefore model results with a solid aircraft do not differ from those with a hollow aircraft and furthermore the solid aircraft solution needs less computing time. The outer boundaries of the model geometry consist of zones were the spatial coordinates are scaled to very large distances in order to simulate an infinite space and to suppress boundary effects (mapped infinite elements (COMSOL, 2006). The triangulated mesh consists of a total number of approximately 230,000 elements with the highest element density in the aircraft model and in the ocean just below the aircraft (see Fig. 4).

The complete problem can be solved for a quasi static case, i.e. displacement currents generally can be neglected. The prerequisite for the quasi static case is a wavelength of the transmitter signal much larger than the dimension of the structures involved. With a frequency of $1990 \mathrm{~Hz}$ we obtain a wavelength of approximately $150 \mathrm{~km}$. The model code obtains the magnetic vector potential $A$ on every gridpoint by solving the following equation:

$\left(i \omega \sigma-\omega^{2} \epsilon_{0} \epsilon_{r}\right) A+\nabla \times\left(\mu_{0}^{-1} \mu_{r}^{-1} \nabla \times A\right)=J$

where $\sigma$ is the electrical conductivity, $\epsilon_{0}$ the electrical permittivity of vacuum and $J$ an externally generated current. $\epsilon_{r}$ and $\mu_{r}$ are the relative electrical permittivity and the relative magnetic permeability and are both set to one, with the consequence that the involved 


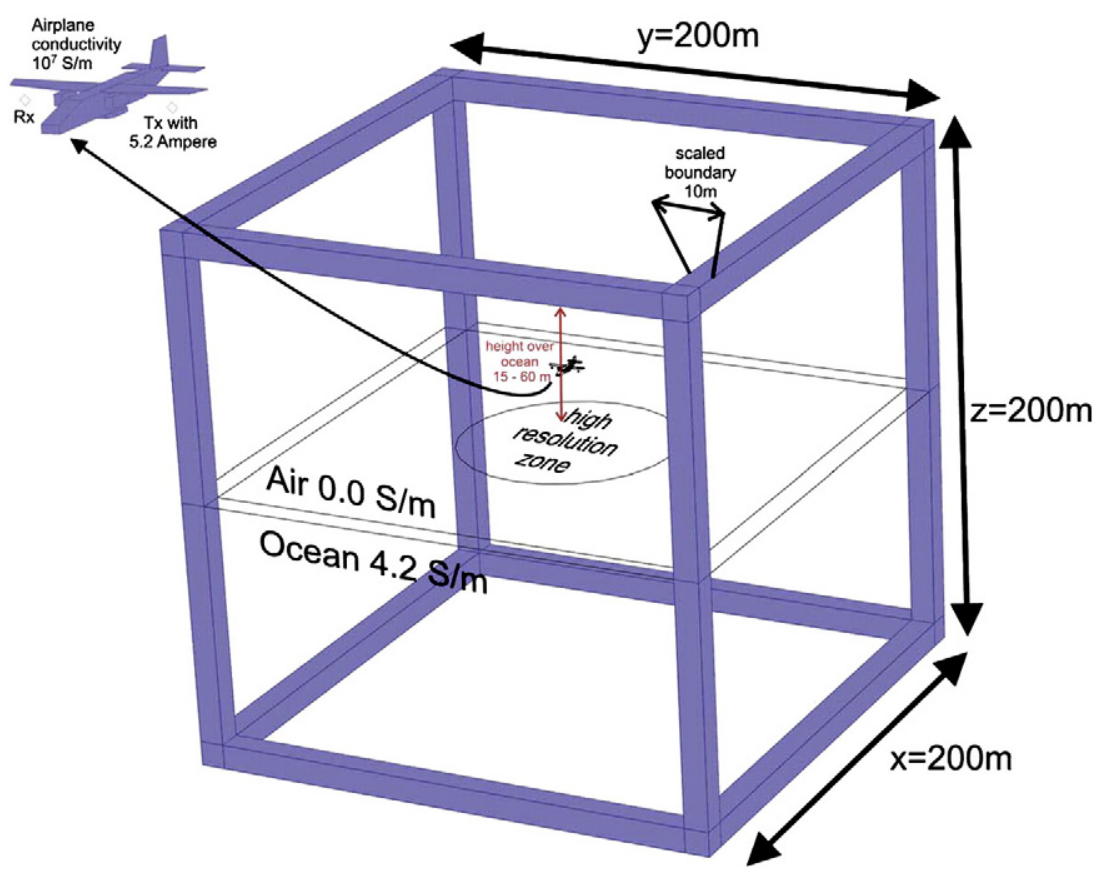

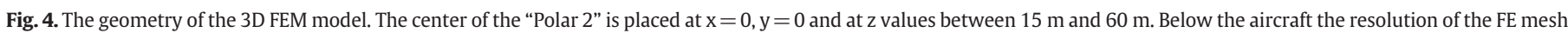

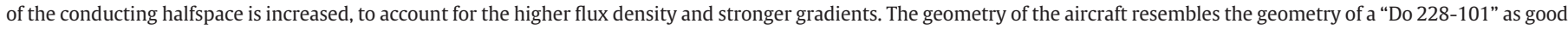
as possible.

structures in the model are neither polarisable nor magnetizable. The magnetic vector potential relates to the magnetic field $B$ by

$B=\nabla \times A$

The Tx-coil is represented by a rectangular wire in the yz-plane with a current $I$ of 5.2 A flowing through it. The receiver $(\mathrm{Rx})$ is defined as a rectangle parallel to Tx with the same dimension. The magnetic flux $\Phi$ within Rx is determined by the numerical integration of $B$ over the area $A_{R x}$ enclosed by the receiver:

$\Phi=\int_{A_{R x}} B \cdot d a$

where $d a$ is the unit vector normal to $A_{R x}$.

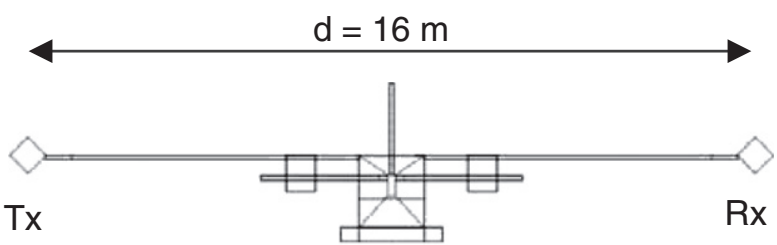

Wing Tip Mounting

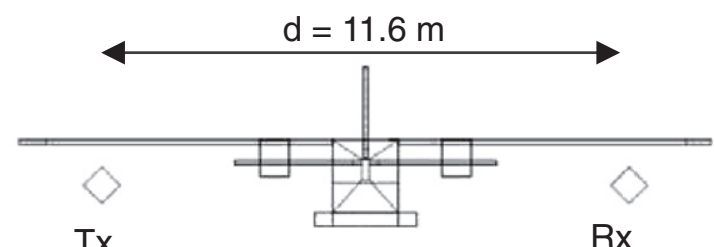

Tx

$\mathrm{Rx}$

\section{Wing Center Mounting}

Fig. 5. View from behind the two aircraft geometries used for all FEM simulations. The two geometries only differ by the position of the Tx and Rx coils representing a wing-tip and a wing-center mounting.
In total we performed three different model experiments to study the effects of:

1. induction in the aircraft body

2. pitch and roll

3. wing deflection

on the EM signal measured by Rx. Every model experiment was conducted under four different settings and different flight heights for both coil configurations. The first setting was without ocean and aircraft and the output signal $S_{P}$ (The term $S$ for signal corresponds to the flux density $\Phi$ from Eq. (12)), the second setting was without the aircraft model to get the output signal $S_{P O}$ ( $\mathrm{PO}$ for primary and ocean), the third was without an ocean and the output signal $S_{P A}$ and the fourth was with all elements shown in Fig. 4 switched on to get the output signal $S_{P O A}$.

The four different settings are necessary in order to determine the different contributions to the EM signal $S_{P O A}$ separately: The primary field $S_{P}$, the ocean response $S_{O}$, the contribution of the aircraft $S_{A}$ and the signal contributing from the coupled aircraft-ocean system together $S_{A O}$ which is identical to $S$ in Eq. (4).

\section{Results}

\subsection{Test flights}

\subsubsection{Accuracy test}

In order to examine the system performance under flight conditions several test flights were done over the North Sea in fall 2006 (Fig. 2). Fig. 6 shows results of a flight which started in $300 \mathrm{~m}$ height, descended down to $20 \mathrm{~m}$ and climbed back again to $300 \mathrm{~m}$. In this way the systems agreement with the calculated response for different flying heights can be evaluated. The sea water conductivity in the study region was measured at the same time by the research ship 'RV Heincke', amounted to $4.2 \mathrm{~S} / \mathrm{m}$ and did not change within the skin depth of about $6 \mathrm{~m}$. Furthermore open water is a good validation target since ice thickness is zero and henceforth laser height and EM derived height must agree. All processing steps described in Chapter 2.2. were applied on these data. In particular the data were corrected for the constant offset caused by the $S_{A}$ signal. Following Eq. (4) the 


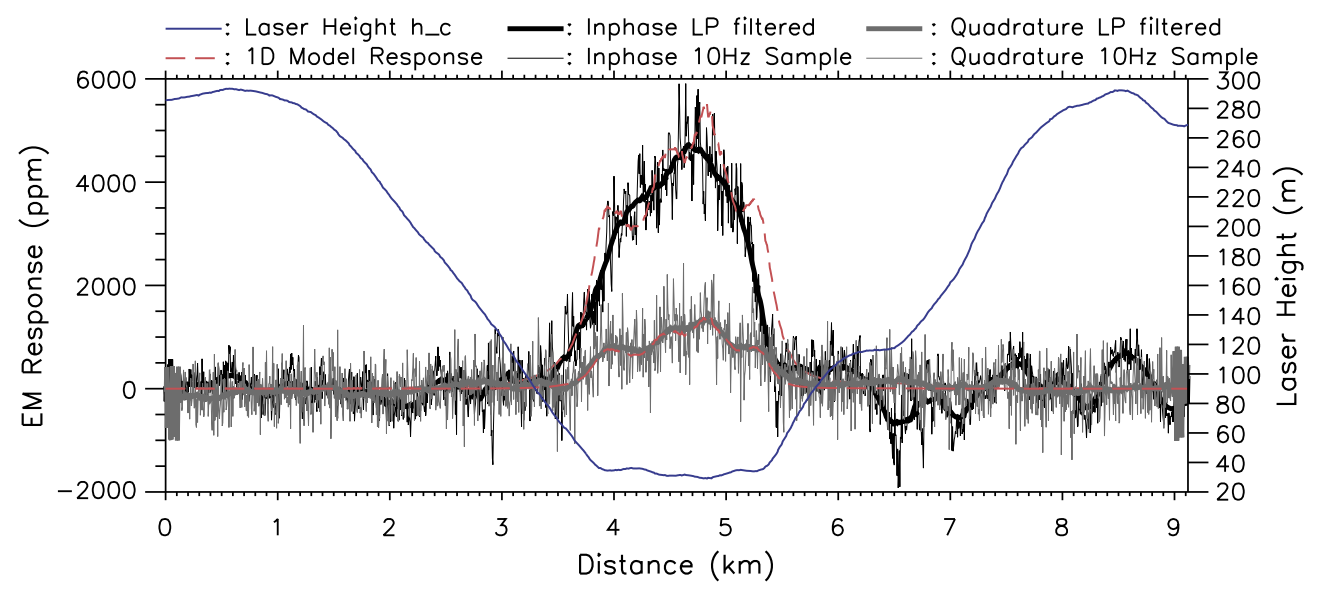

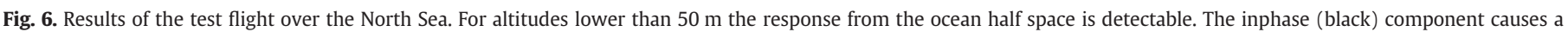
stronger response than the quadrature (gray) component. The quadrature component is in better agreement with the theoretical ocean response based on a 1D model.

amplitude of $S_{A}$ was in the order of $35,000 \mathrm{ppm}$. Significant Inphase and Quadrature signal from the ocean emerged for altitudes below $50 \mathrm{~m}$. The $10 \mathrm{~Hz}$ signal is very noisy with signals of on average $+/-500$ ppm probably caused by high frequency vibration of the antenna coils. This vibration noise is normally distributed and is also present when the aircraft is on ground with the engines switched on. It can be reduced by applying a low pass (LP) filter which also leads to a loss of horizontal resolution. As LP filter a 10 point running window was used. After the averaging filter was applied the Quadrature trace is in good agreement with the 1D model curve, deviating by less than $\pm 20 \mathrm{ppm}$. In contrast the Inphase trace is subject to variations which are not directly caused by changes in altitude. Possible reasons are pitch \& roll of the aircraft, wing flexure and/or EM coupling between aircraft and ocean. These were examined by the 3D finite-element model study.

In Fig. 7 I and $Q$ are plotted against laser height together with the 1D model curve. The deviation of each sample from the model curve along the $\mathrm{x}$-axis is a measure for the accuracy of the system. The data shown in Fig. 7 were transferred into ice thickness (which should be zero) as described in Section 2.2.5., by the difference between laser height and EM height. The results for the low altitude part of the test flight is shown in Fig. 8. Despite its weaker response the $Q$ signal

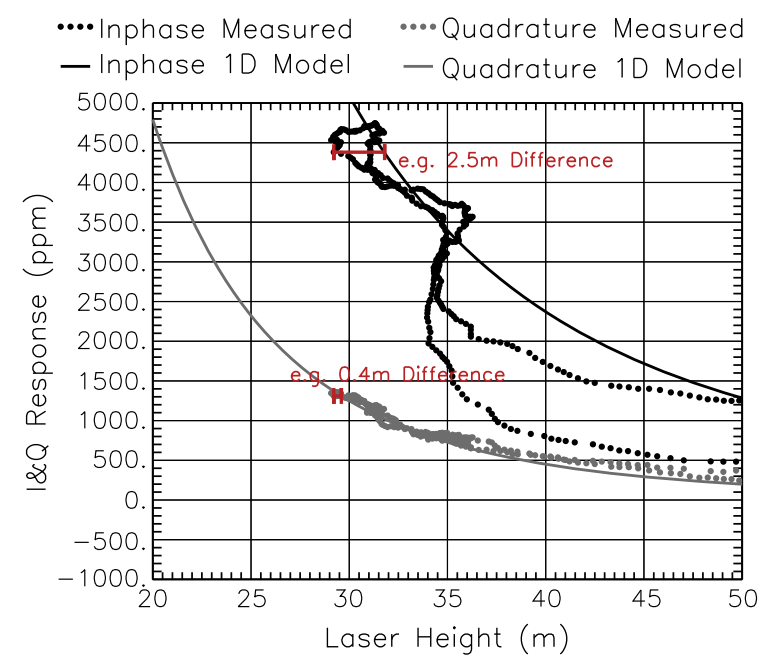

Fig. 7. Inphase and quadrature response versus laser height together with $1 \mathrm{D}$ model curves. The distance between each sample and the model curve along the $\mathrm{x}$-axis reflects the achievable sea-ice thickness accuracy. For the ideal case (noise free) all data points should lie on the respective model curves. The inphase component deviates strongly due to heavy noise which is particular pronounced when the aircraft is descending or climbing (here for the altitude range 35-50 m). agrees better with the model curve because it is less affected by the disturbing signals mentioned above. However, for a distance of $1.5 \mathrm{~km}$ a vertical accuracy of $+/-0.5 \mathrm{~m}$ was reached (marked by the orange zone in Fig. 8). This can be considered as the maximum achievable accuracy for the prototype ice thickness system used during the test flights. Furthermore, these results suggest that a minimum flight height of $35 \mathrm{~m}$ is required but even lower flight heights are recommended since the EM response increases exponentially with decreasing height and the vertical accuracy should be better than $\pm 0.1 \mathrm{~m}$.

\subsubsection{Wing flexure test}

A second test flight was performed in altitudes of $630 \mathrm{~m}$ and aimed on the signal emerging from wing flexure. Up and down flight maneuvers caused the elastic wings to deflect strongly due to upward and downward directed inertia forces. The inphase and quadrature responses for this flight are shown in Fig. 9. A strong signal of approximately $\pm 7000 \mathrm{ppm}$ could be detected on the inphase component whereas the quadrature component is almost unaffected. Since the wing positions, and therewith the antenna positions, are not recorded, we further examined the wing flexure effect during the 3D FEM model study.

\subsection{D modeling}

\subsubsection{Induction in the aircraft}

In the first model experiment the EM signal from the ocean $\left(S_{O}\right)$, the aircraft anomaly $\left(S_{A}\right)$ and the ocean signal plus aircraft anomaly $\left(S_{A O}\right)$ were calculated to fully explain all contributions to $S_{A O}$ resulting from induction processes in the aircraft body. Furthermore, the frequency dependency of $S_{A O}$ was examined. The left graph of Fig. 10 shows that the inphase for a frequency of $1990 \mathrm{~Hz}$ is close to the asymptotic maximum and that the quadrature is decreasing for increasing frequencies. Concerning the aircraft anomaly our first assumption was that the aircraft causes a constant signal independently of the height over the ocean. If this is true, a simple subtraction of $S_{A}$ from the signal measured in free space would remove the aircraft effect. In order to verify this assumption several model runs were performed where the height of the aircraft over the ocean changed between $15 \mathrm{~m}$ and $60 \mathrm{~m}$ in steps of $2.5 \mathrm{~m}$ (see Fig. 4). The following equations were used to calculate the response signals in ppm from the model output, where all signals $S$ are taken in their complex form:

$S_{O}=\frac{\left(S_{P O}-S_{P}\right) \cdot 10^{6}}{S_{P}}$ 


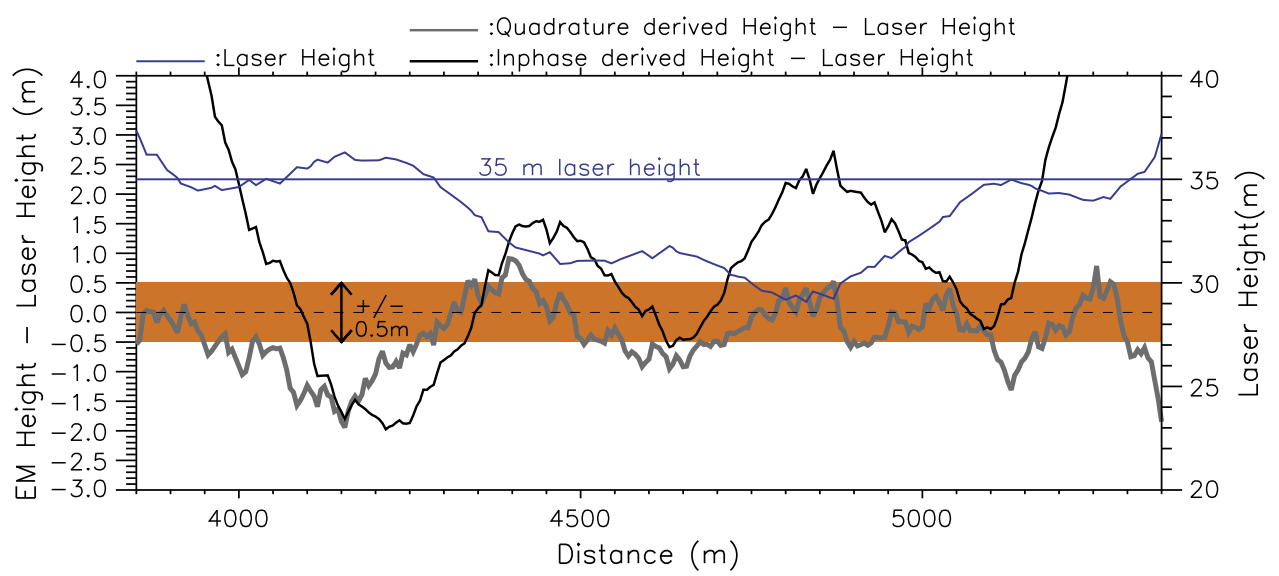

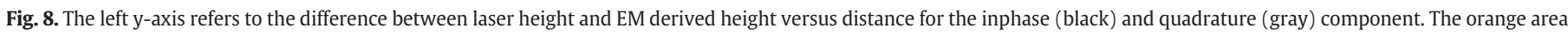

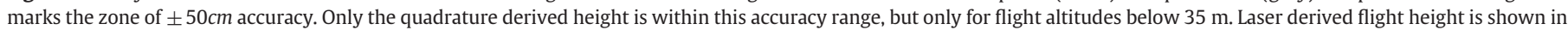
blue and the right $y$-axis refers to it.

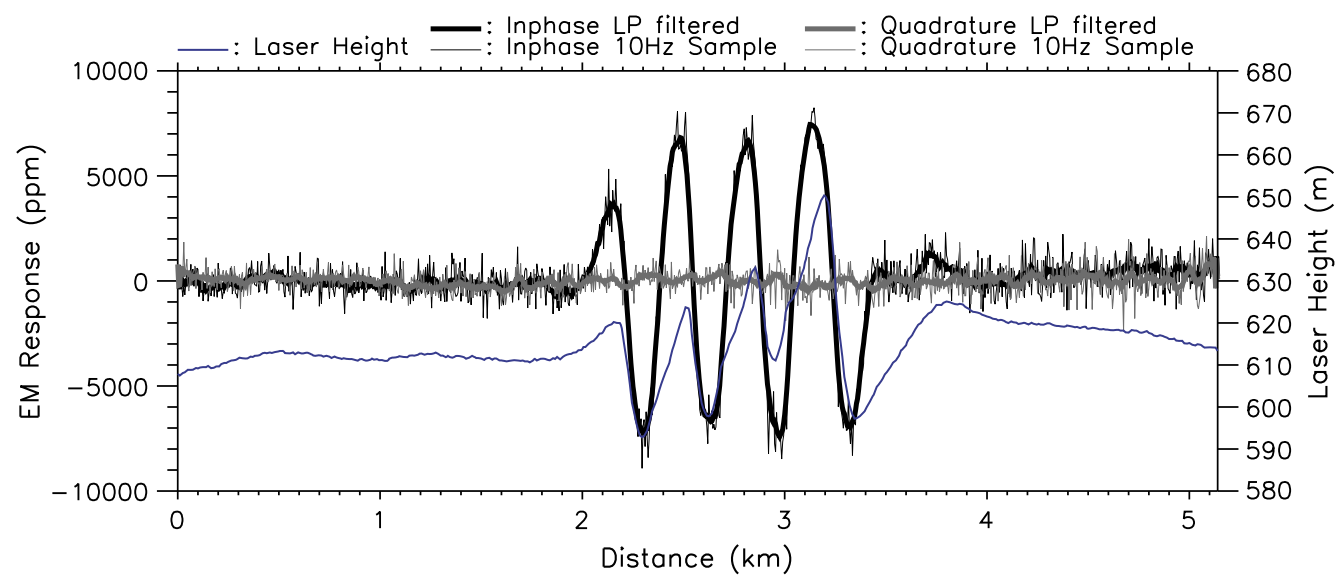

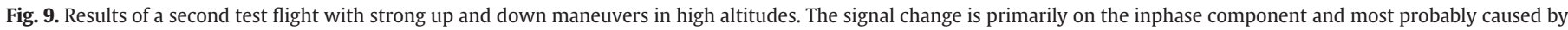
wing deflection.

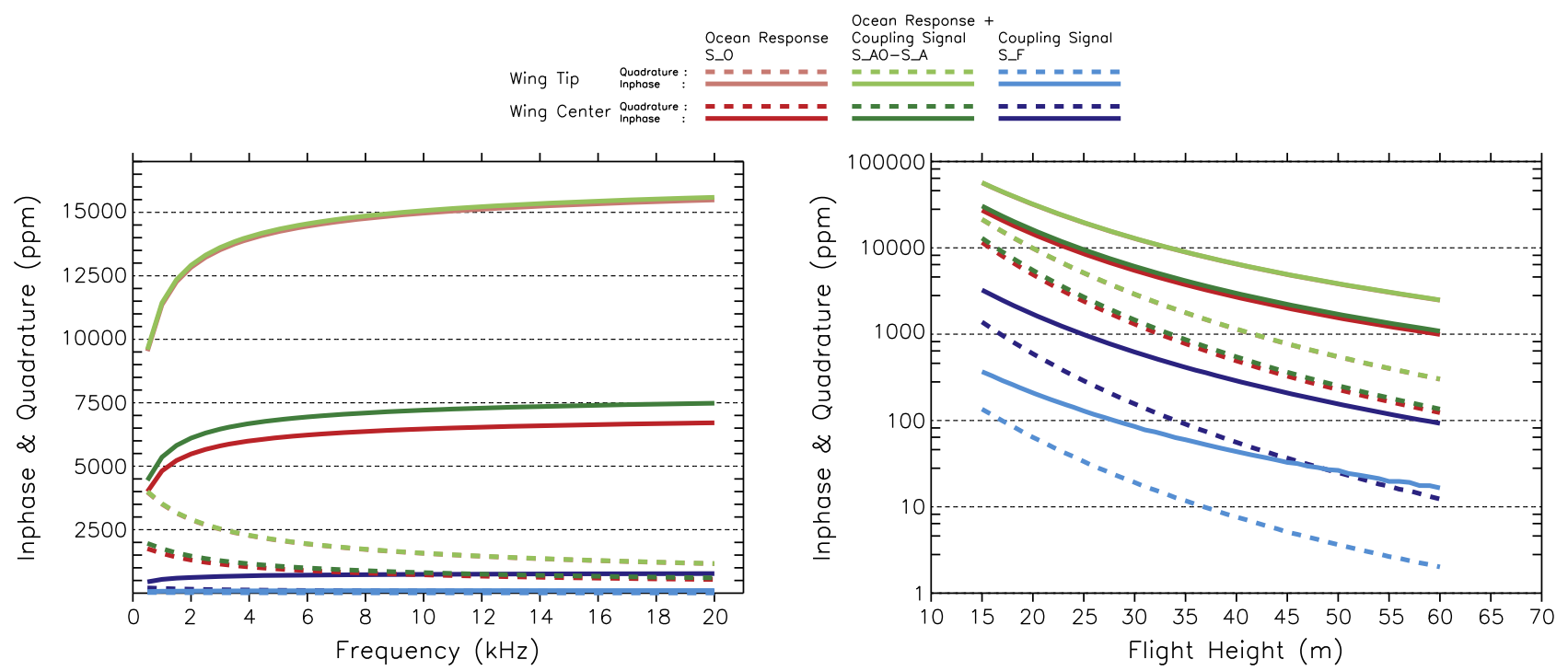

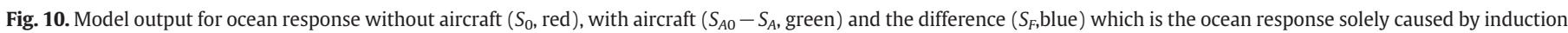

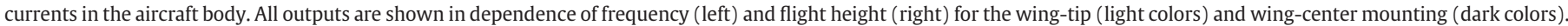


$S_{A}=\frac{\left(S_{P A}-S_{P}\right) \cdot 10^{6}}{S_{P}}$

$S_{A O}=\frac{\left(S_{P O A}-S_{P}\right) \cdot 10^{6}}{S_{P}}$

$S_{A}$ amounted to a constant signal of $33,260 \pm 160 \mathrm{ppm}$ on the inphase and $71 \pm 3$ ppm on the quadrature where the \pm values are related to the numerical accuracy. The much larger inphase response on $S_{A}$ results from the high conductivity of the aircraft body of $3.77 \cdot 10^{7} \mathrm{~S} / \mathrm{m}$ causing only a small phase shift relative to $S_{P}$. When $S_{A}$ is constant, it can be removed by subtraction from $S_{A O}$ but surprisingly we found

$S_{A O}-S_{A}=S_{O}+S_{F}$

where $S_{F}$ is the signal caused by a coupling between aircraft and ocean. Both, $S_{O}$ and $S_{F}$ depend on the height over the ocean. In Fig. 10
$S_{O}, S_{F}$ and $S_{A O}-S_{A}$ are plotted for both coil configurations, wing tip and wing center mounting. For a typical flight height of $35 \mathrm{~m} S_{F}$ amounts to $373 \mathrm{ppm}$ on the inphase and $100 \mathrm{ppm}$ on the quadrature component for the wing center configuration. For the hypothetical wing tip configuration $S_{F}$ is much weaker and amounts to $80 \mathrm{ppm}$ and $10 \mathrm{ppm}$ on inphase and quadrature, respectively.

\subsubsection{Pitch and roll}

The second model experiment estimated the effect of variable pitch and roll on $S_{A O}$ for both coil configurations. For this purpose the conducting halfspace was tilted instead of the aircraft (see Fig. 11a). The advantage of this approach is that the calculation of $B$ at $\mathrm{Rx}$ is limited to the easier calculation of $B_{x}$. The roll and pitch angle in the model varied between 0 and $17^{\circ}$. During test flights usual pitch and roll angles of $\pm 7^{\circ}$ emerged with extreme values of $\pm 15^{\circ}$. Following the study of (Fitterman and Yin, 2004) we introduce the response

a

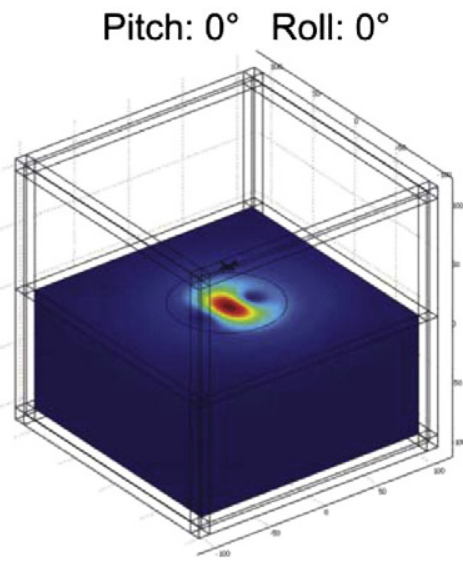

Pitch: $15^{\circ}$ Roll: $0^{\circ}$
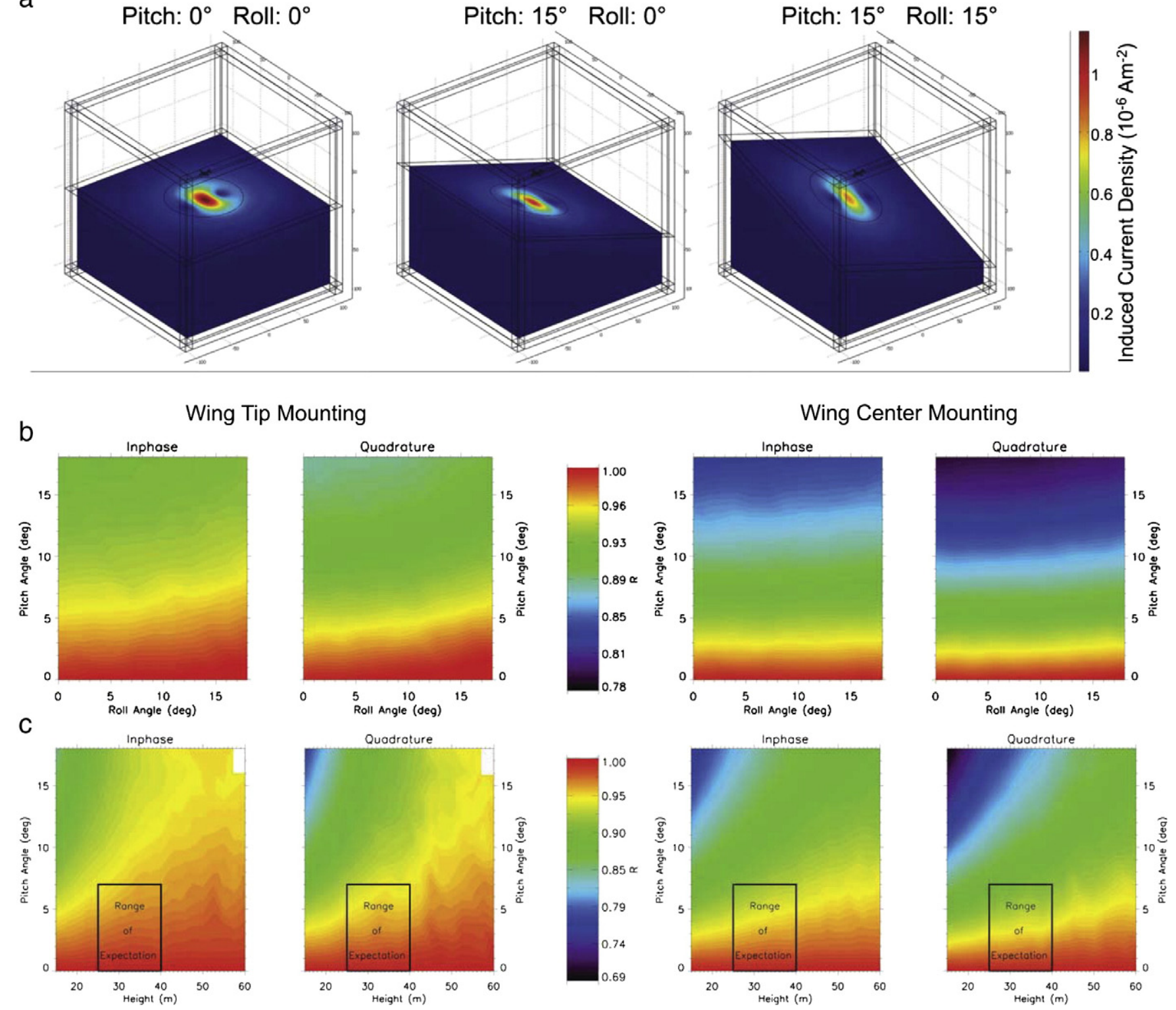

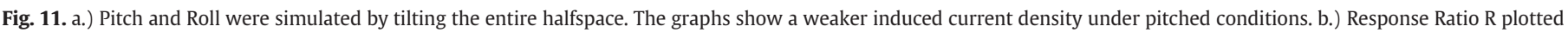

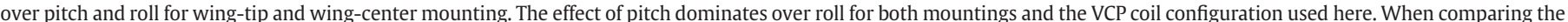

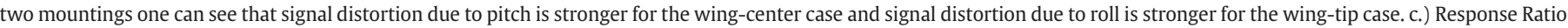

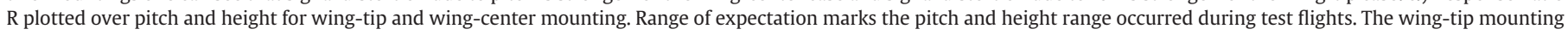
produces a weaker signal distortion. Irregularities in the wing-tip contour plot for high altitudes indicate the numerical accuracy of the used FEM models. 
ratio $R$ which is the ratio of $S_{A O}$ when pitch and roll is present to $S_{A O}$ when pitch and roll is zero:

$R($ pitch, roll $)=\frac{S_{A O}(\text { pitch }, \text { roll })}{S_{A O}(0,0)}$

In Fig. $11 \mathrm{~b} R$ is plotted for a constant flight height of $30 \mathrm{~m}$. Obviously pitch has a much stronger effect than roll for the VCP configuration, since roll does not change the orientation of the dipole axis relative to the ocean which is in agreement with the analytical results of (Fitterman and Yin, 2004). For a HCP configuration both, pitch and roll, would change the axis of the magnetic dipole relative to the ocean and consequently both would affect $S_{A O}$. With increasing pitch and for the wing center mounting $I$ and $Q$ of $S_{A O}$ both get weaker by for instance $7 \%$ and $9 \%$ for typical roll and pitch values of $5^{\circ}$ (Fig. 11b right graph). For the wing tip configuration the effect of pitch is approximately half as strong as for the wing center configuration, whereas roll has a slightly stronger effect for the wing tip mounting (Fig. 11b left graph), since the wingtips move closer to the ocean for the same roll angle. Extremer pitch and roll of $10^{\circ}$ occur during ascending, descending or curve maneuvers, which decrease $S_{A O}$ for the wing center mounting by about $20 \%$ and $15 \%$. But sections with such heavy pitch are normally cut out from the data set. For the further construction of a correction chart, roll is neglected and set to zero due to its minor influence. Instead we examined the pitch effect on inphase and quadrature for different heights between $15 \mathrm{~m}$ and $60 \mathrm{~m}$. $R$ is shown for different heights and pitch angles in Fig. 11c, which is identical to the correction chart for data processing. For usual pitch angles and flight heights of $25-40 \mathrm{~m}$ a maximum change of $10 \%$ and $13 \%$ can be expected for the inphase and quadrature components respectively (Fig. 11c right graph). Again, approximately half the maximum signal change can be expected for the wing tip mounting (Fig. 11c left graph).

\subsubsection{Wing deflection}

In the third model experiment the influence of wing deflection on the primary field at the receiver $S_{P}$, the aircraft anomaly $S_{A}$ and the ocean response $S_{O}$ was examined for the typical flight height of $30 \mathrm{~m}$. The wing deflection angle, which is the angle between wing and fuselage, was varied between $-5^{\circ}$ and $5^{\circ}$ with an increment of $0.1^{\circ}$ (Fig. 12). The position of the coils were modified accordingly.

In Fig. $13 S_{P}, S_{O}$ and $S_{A}$ are plotted versus deflection angle for both coil configurations. From all contributions to the EM signal presented

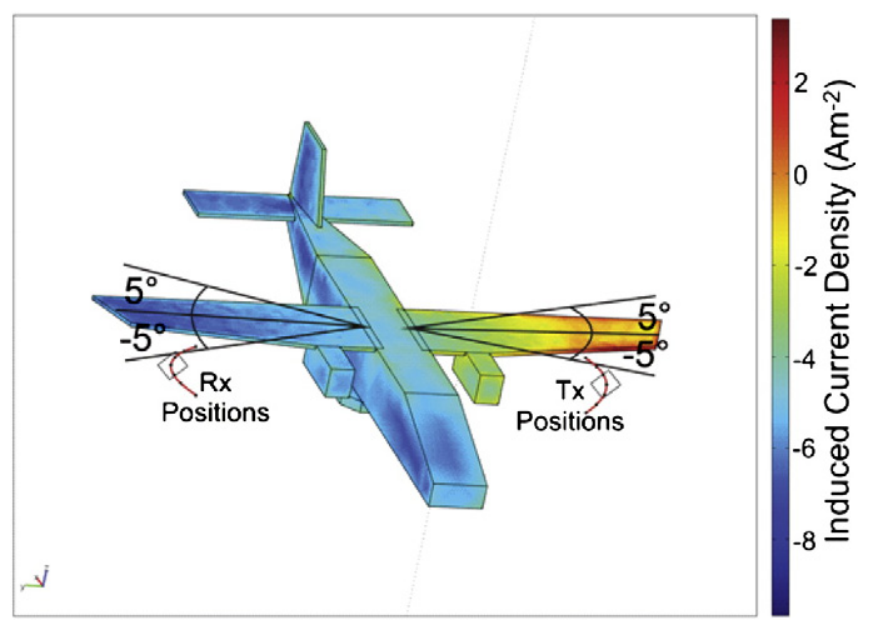

Fig. 12. Wing deflections were simulated by a change of the angle between fuselage and wings by up to $\pm 5^{\circ}$. The positions of transmitter and receiver were adjusted accordingly. Colors indicate the induced current density. so far, wing deflection has the highest potential to disturb the signal. The inphase component of $S_{P}$ changes by up to $10,000 \mathrm{ppm}$ just because of the change in system geometry, particularly in the antenna separation distance $(d)$ which influences the signal with $d^{3}$ (see Eq. (7)). Of the same order of magnitude is the change in the inphase component of $S_{A}$ which is between -3500 and $7800 \mathrm{ppm}$ for the wing center mounting and between -1500 and 2500 ppm for the wing tip mounting. This can only be attributed to changing induction currents in the aircraft body. The influence on the quadrature component of $S_{A}$ is negligible. Closer to the ocean $(30 \mathrm{~m})$ even $S_{O}$ changes with wing deflection, due to an effective height change of the antennas over the ocean halfspace. The change of $S_{O}$ ranges between $-250 \mathrm{ppm}$ and $150 \mathrm{ppm}$ for the wing center mounting and between $-700 \mathrm{ppm}$ and $500 \mathrm{ppm}$ for the wing tip mounting and a maximum deflection angle of $\pm 5^{\circ}$.

\section{Discussion}

A high signal to noise ratio is of special importance for quantitative and high resolution AEM measurements like sea-ice thickness sounding. Here we have shown and quantified noise sources appearing for a fixed wing system over a homogeneous halfspace. Even after a series of standard processing steps of phase-, drift-, pitchand roll correction, conversion to $\mathrm{ppm}$ and low pass filtering residual unwanted signals remain. By means of 3D FEM modeling we quantified three processes contributing to this residual noise. In particular this was the additional ocean response caused by induction currents in wings and fuselage, pitch movement and wing deflection in presence of an aircraft over a good conducting halfspace. The first two noise sources could be addressed during data processing whereas wing-deflection noise cannot be corrected since the relative position of antenna coils and wings are not recorded. From this three noise sources the by far strongest contribution comes from wing deflection. However, additional noise sources exist, emerging from e.g. the aircraft engines, which are not addressed in this publications but which may further explain the large noise on the "Polar 2" prototype instrument.

In Fig. 14, all processing steps applied to the test data set (the one shown in Fig. 6) are evaluated by comparing the difference between FEM model result and measured data after each processing step (Fig. 14). The biggest improvement is obtained by the drift correction (difference between green and red in Fig. 14) showing that in real systems drift has an enormous contribution to the signal. However, the improvement of the corrected signal shows that the majority of the drift can be corrected by a first drift correction as explained in Chapter 2.2.3., but certainly a non linear and short term drift component during the time of measurement in low altitudes remains, which is hard or even impossible to correct. Nevertheless, some signal undulations which are caused by transmitter voltage variations can be minimized by a Tx reference voltage correction (difference between red and blue (overlaid with gray) in Fig. 14). The smallest improvement of the signal is obtained by a pitch (maximum pitch was $7^{\circ}$ ) correction of the laser height (Chapter 2.2.5) and the EM signal (Chapter 3.2.2.) which changes the signal by about a maximum of $35 \mathrm{ppm}$ and $75 \mathrm{ppm}$ for the quadrature and inphase respectively. Thus pitch (and also roll for a HCP configuration) is of importance for accurate thickness measurements, but for a fixed wing system it has a minor effect in comparison to wing deflection. The residual noise (gray in Fig. 14) can be assigned to wing deflection and or nonlinear drift components caused by e.g. sensitivity of involved electronic components to temperature changes and air pressure changes.

For the prototype system used in this study wing deflection and/or the relative position of the antenna coils were not recorded. But the second test flight in high altitudes of $630 \mathrm{~m}$ supports the wing deflection results from the FE model study (Fig. 9). In agreement with Fig. 13 the wing deflection signal of approximately $\pm 7000 \mathrm{ppm}$ is 


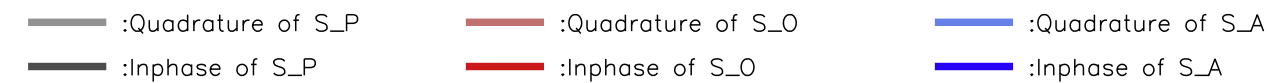

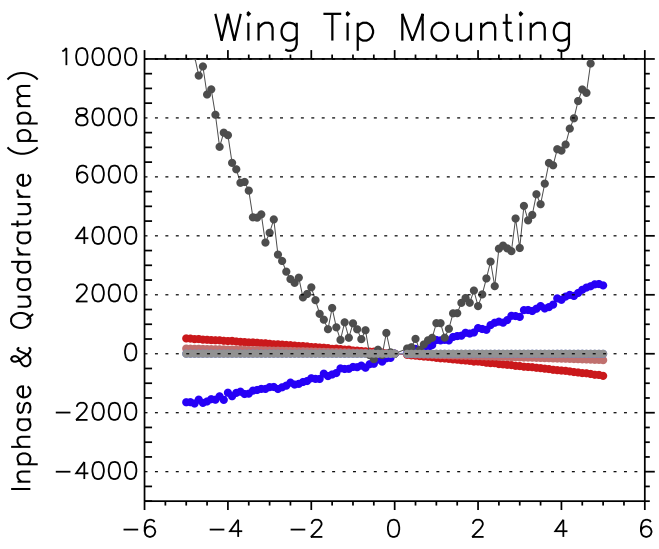

Wing Center Mounting
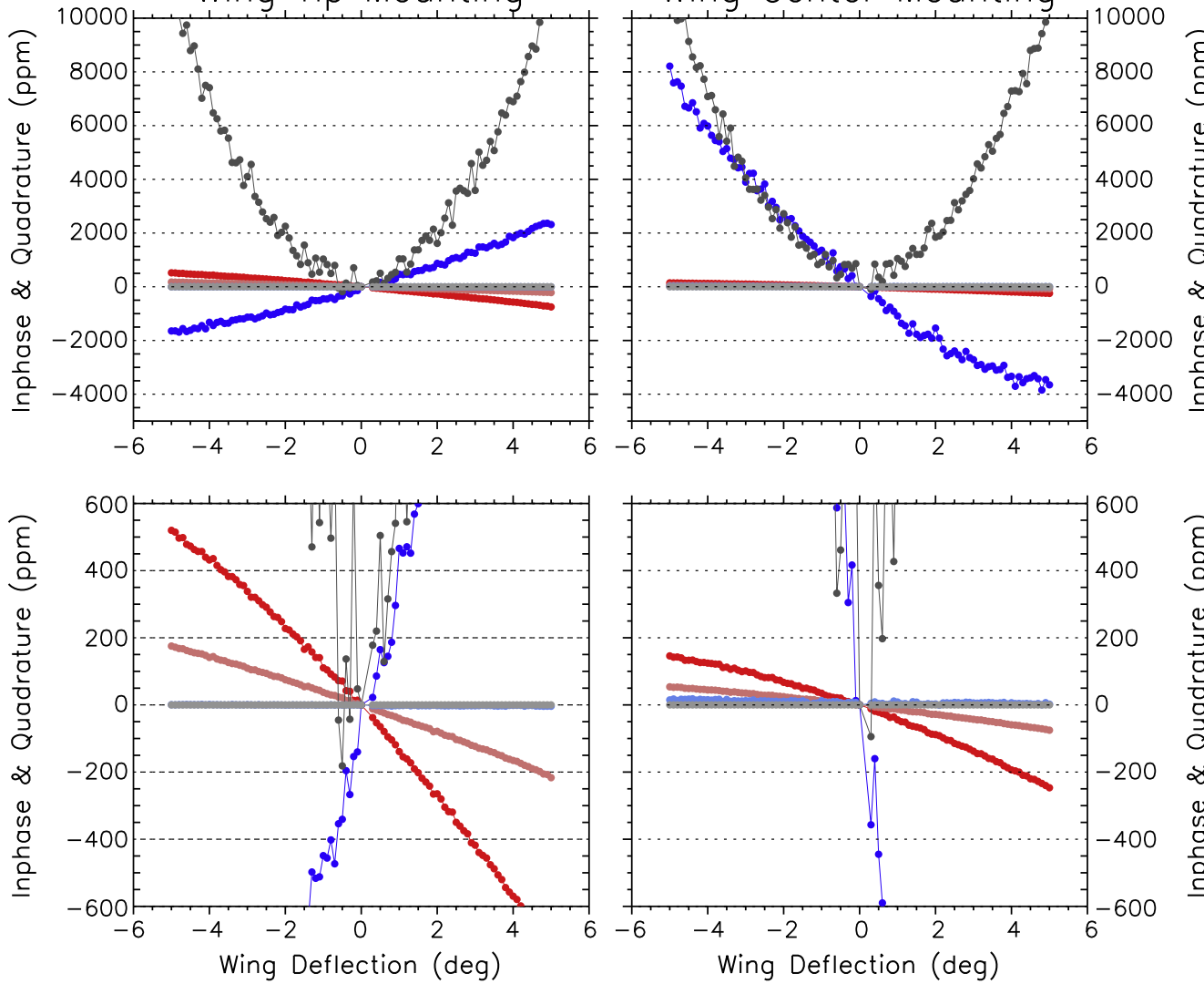

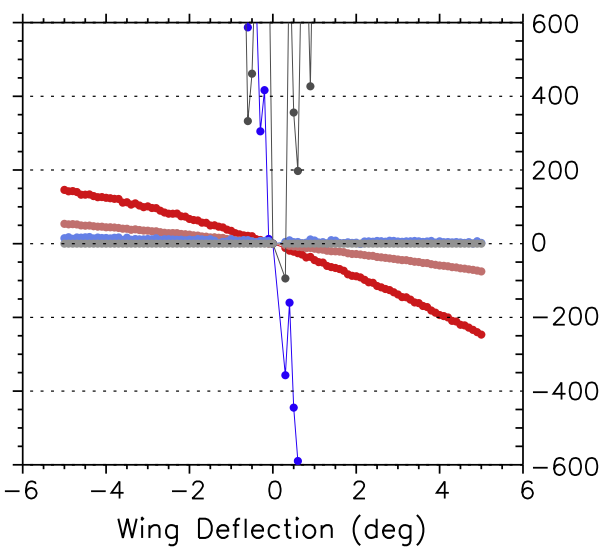

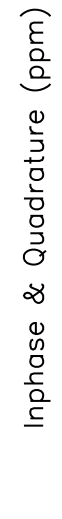

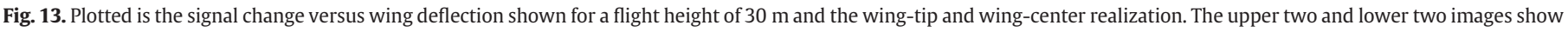

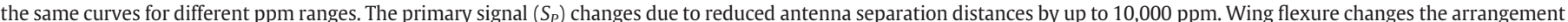

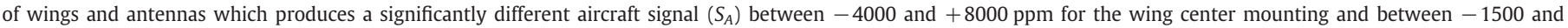
$+2500 \mathrm{ppm}$ for the wing tip realization. A change in the ocean response $\left(S_{O}\right)$ is noticeable primarily caused by a reduced or increased distance of the antennas to the ocean.

primarily on the inphase component. The inphase signal change is positive and negative which justifies the following conclusion. The first conclusion is that the inflight wing position and therefore the antenna separation distance differs to the situation on ground even during calm flight conditions with the consequence that deflection in one direction increases the antenna distance and deflection in the other direction decreases the antenna distance. In Fig. $13 S_{P}$ can only be positive because the antenna separation distance always becomes smaller when we assume the horizontal wing position as the neutral one. However, since the in flight antenna position could not be
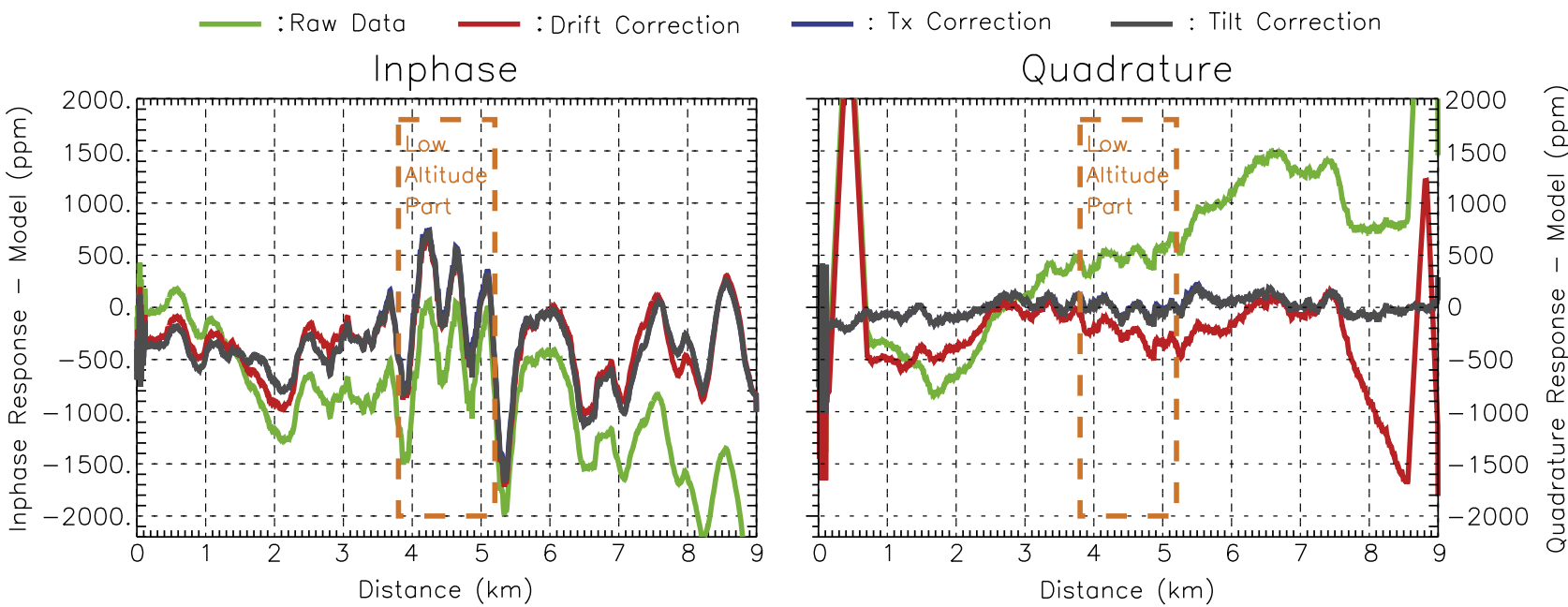

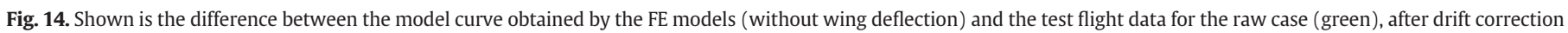
(red), after Tx correction (blue) and after pitch correction (gray). The residual noise is caused by wing deflection and non linear drift components. 
measured, a direct comparison between model results and real data is difficult. But the general comparison of both results shows an agreement in the occurring signal magnitudes.

Another interesting point is, why wing deflection influences the inphase component of $S_{A}$ much stronger than the quadrature component. The answer is given by the following formula in combination with the high conductivity of the aircraft (in the FE model set to $3.77 \cdot 10^{7}$ ) (Telford et al., 1990, p.351):

$\theta_{P}-\theta_{S}=\left(\frac{\pi}{2}+\tan ^{-1} \frac{\omega L_{S}}{\rho_{S}}\right)=\left(\frac{\pi}{2}+\phi\right)$

where $\theta$ is the phase of the primary and secondary field respectively and $L_{S}$ and $\rho_{S}$ are inductance and resistance of the conductor causing the EM response (in this case the aircraft body and/or the ocean halfspace). With a high conductivity (i.e. low resistance) $\omega L_{S} / \rho_{S} \rightarrow \infty$ and $\phi \rightarrow \pi / 2$ and therefore the overall phase shift is $180^{\circ}$ relative to the primary field i.e. for a perfect conductor all the signal is on the inphase component.

\section{Concluding remarks and outlook}

In this study we quantified the biggest noise contributors occurring with an aircraft based frequency domain electromagnetic instrument with the receiver and antenna coils fixed under the wings. Two test flights with a prototype instrument and three finite-element 3D modeling studies were presented. The situation was that of vertical coplanar antenna coils over a conducting homogeneous halfspace in presence of a highly conductive aircraft body. The aircraft geometry used in the 3D model study was oriented on the "Polar 2" prototype system, with the antennas mounted below the center of each wing, and on a hypothetical system with the antennas mounted on the wingtips of "Polar 2". As one conclusion the results of the FEM models show the superiority of a wing tip realization over a wing center realization, mainly due to the increased antenna separation distance and the consequently increase of the EM signal. The prototype EM instrument showed the severeness of the noise present on a fixed wing system, as the maximum achievable sea-ice thickness accuracy was only $\pm 0.5 \mathrm{~m}$ using the quadrature component. The inphase component is more sensitive to changes in antenna distance and to induction currents in the aircraft body and therefore it is less suitable for ice thickness retrieval than the quadrature component (at least for the prototype instrument used here) even when the inphase ocean response is stronger than the quadrature response. The results of this paper are important for the construction and usage of future AEM seaice thickness instruments whenever the antennas are mounted close to the body of the aircraft. For the sea-ice application the aircraft anomaly is particularly strong due to mutual induction in the conducting ocean half space but certainly the described effects also influence other quantitative AEM measurements, e.g. all free space effects are of similar importance independently of the measurement target. Finally, we suggest that a fixed wing EM sea-ice thickness sounder should not be operated without an adequate measurement of the relative coil position, e.g. by a laser distance meter pointing from the fuselage to the antennas. In order to achieve an ice thickness accuracy of $\pm 0.1 \mathrm{~m}$ the antenna separation distance should be measured with an accuracy of more than $1 / 10 \mathrm{~mm}$. As an alternative we suggest to mount antennas for such highly quantitative EM measurements on the more rigid fuselage and not on the wings. Another option is to use fixed wing aircrafts with a winch and which are therefore capable to carry external swing loads. Under such circumstances the EM system could be integrated into a so called "Bird", an aerodynamically shaped shell which is dragged behind the aircraft (Haas et al., 2010). However, winching of external loads may as well cause problems within the worst case complete lost of the EM instrument and only a few aircrafts available have this option at all.

\section{Acknowledgments}

This work received additional funding by the EU project DAMOCLES, a contribution to the International Polar Year 20072008. Furthermore we thank all involved companies and institutions, in particular 'Optimare Sensorsyteme AG' for the technical support and the handling of the licensing procedure, 'Deutsches Zentrum für Luft- und Raumfahrt' (DLR) for the operation of the Polar2 and the licensing procedure and 'Leichtwerk AG' for the construction of the outer antenna shells. Furthermore we are indebted to the following persons: Thomas Garbrecht and Jürgen Höltig from Optimare AG, Stefan Seydel, Andreas Hahn and Hans Juergen Berns from DLR and finally Andreas Herber for the support from the AWI logistics. Without any of these persons the test flights would never have been successfully conducted.

\section{References}

COMSOL, 2006. Comsol Multiphysics, Manual AC/DC Module: Users Guide.

Fitterman, D., Yin, C., 2004. Effect of bird maneuver on frequency-domain helicopter EM response Sep.-Oct. Geophysics 69 (5), 1203-1215.

Haas, C., Hendricks, S., Doble, M., 2006. Comparison of sea ice thickness distribution in the Lincoln Sea and adjacent Arctic Ocean in 2004 and 2005. In: Langhorne, P. Squire, V. (Eds.), Ann. Glaciol., Vol. 44, pp. 247-252.

Haas, C., Pfaffling, A., Hendricks, S., Rabenstein, L., Etienne, J.-L., Rigor, I., 2008. Reduced ice thickness in Arctic Transpolar Drift favors rapid ice retreat SEP. 3 Geophysical Research Letters 35 (17).

Haas, C., Lobach, J., Hendricks, S., Rabenstein, L., Pfaffling, A., 2009. Helicopter-borne measurements of sea ice thickness, using a small and lightweight, digital EM system Mar. Journal of Applied Geophysics 67 (3, Sp. Iss. SI), 234-241.

Haas, C., Hendricks, S., Eicken, H., Herber, A., 2010. Synoptic airborne thickness surveys reveal state of Arctic sea ice cover MAY 14 Geophysical Research Letters 37.

Keller, G., Frischknecht, F., 1966. Electrical Methods in Geophysical Prospecting. Oxford Pergamon Press.

Kovacs, A., Valleau, N., Holladay, J., 1987. Airborne electromagnetic sounding of sea ice thickness and sub-ice bathymetry OCT. Cold Regions Science and Technology 14 (3), 289-311.

Kovacs, A., Holladay, J., Bergeron, C., 1995. The footprint altitude ratio for helicopter electromagnetic sounding of sea-ice thickness - comparison of theoretical and field estimates MAR.-APR. Geophysics 60 (2), 374-380.

Levaniemi, H., Beamish, D., Hautaniemi, H., Kurimo, M., Suppala, I., Vironmaki, J., Cuss, R.J., Lahti, M., Tartaras, E., 2009. The JAC airborne EM system: AEM-05 March Journal of Applied Geophysics 67 (3, Sp. Iss. SI), 219-233.

Multala, J., Hautaniemi, H., Oksama, M., Lepparanta, M., Haapala, J., Herlevi, A., Riska, K., Lensu, M., Dec 1996. An airborne electromagnetic system on a fixed wing aircraft for sea ice thickness mapping. Cold Regions Science and Technology 24 (4), 355-373.

Pfaffling, A., Haas, C., Reid, J.E., 2007. Direct helicopter EM - sea-ice thickness inversion assessed with synthetic and field data Jul-Aug. Geophysics 72 (4), F127-F137.

Poikonen, A., Sulkanen, K., Oksama, M., Suppala, I., 1998. Novel dual frequency fixedwing airborne em system of geological survey of finland (gtk). Exploration Geophysics 29, 46-51.

Prinsenberg, S., Holladay, J., Lee, J., 2002. Measuring ice thickness with eisflow ${ }^{\mathrm{TM}}$, fixed-mounted helicopter electromagnetic-laser system. 12th International Offshore and Polar Engineering Conference: Conference Proceedings, 1, pp. 737-740.

Rabenstein, L. Hendricks, S., Martin, T. Haas, C., 2010. Thickness and surface-properties of different sea-ice regimes within the Arctic Trans Polar Drift: data from summers 2001, 2004 and 2007. Journal of Geophysical Research 115.

Steinhage, D., Nixdorf, U., Meyer, U., Miller, H., 2001. Subglacial topography and internal structure of central and western Dronning Maud Land, Antarctica, determined from airborne radio echo sounding Jul. Journal of Applied Geophysics 47 (3-4), 183-189.

Suppala, I., Oksama, M., Hongisto, H., 2005. Gtk airborne em system: characteristics and interpretation guidelines. In: Airo, M.E. (Ed.), Geological Survey of Finland 39, 103-118 Special paper.

Telford, W., Geldart, L., Sheriff, R., 1990. 2nd Edition. Applied Geophysics, Vol. 2. Cambridge University Press, Cambridge. ISBN: 0-521-33938-3.

Wait, J., 1955. Mutual electromagnetic coupling of loops over a homogeneous ground July Geophysics 20 (3), 630-637.

Ward, S., Hohmann, G.W., 1988. Electromagnetic theory for geophysical applications, In: Nabighian, M.E. (Ed.), 1st Edition. Electromagnetic Methods in Applied Geophysics, Vol. 1. Society of Exploration Geophysicists. ISBN: 1-56080-069-0. 